\title{
Methods, theory, and behaviour change
}

Adequate methods for studying the effects of policies and interventions on the interactions between transport and health are important for increasing our understanding of the field. This issue includes a number of papers that have developed or used new methodological approaches, or combined data sources in innovative ways. Many existing methods of measuring physical activity and behaviour are labour intensive or subject to reporting bias and it is encouraging to see novel approaches of reliably quantifying data using new technology. Many of the papers in this issue have used new approaches to address the critical issue of measuring and supporting increases in active travel, a key policy aim for most countries (Hosking et al, 2011).

The degree to which the built environment supports walking is an important issue but hard to measure, and will no doubt feature strongly in this journal's special issue on the built environment, transport and health, due out later in 2016. Kurka et al (2016) have evaluated a new online tool (MAPS) against field audits for measuring land use in the USA. This is an important constituent of walkability models, that assess the potential for people to walk to desired facilities (Christiansen et al, 2016l; Zhang, 2006). Taking a different approach, Pizarro et al (2016) used a web-based tool (PALMS) to combine GPS and accelerometry data to measure active travel to school in Portugal, while Bopp et al (2016) developed a smartphone app to promote active travel in young people attending college in the USA. Their approach was designed to ensure the app included the features considered most important by the target users, such as route planning, travel time, weather, and bike parking on campus. Motivational messages were included as information about what the user has accomplished.

Brondeel et al (2016) linked household travel survey data with accelerometry in a sub-sample to investigate socio-economic differences in transport-related physical activity in adults. They used random forest prediction plots. This builds on the concept of decision trees, using 'forests' of multiple 'trees' to enable a system to learn and provide better predictions (Blackwell, 2012). Broadstock and Collins (2016) also used national travel survey data in their analyses, taking an unobserved components approach to assess the demand for active travel while allowing for partially unobservable generalized cost effects. Not surprisingly, income effects on active travel are greater for lower income households, but there is also some seasonal substitution. They recommend that active travel policies need to be adapted to take into account the effects of season.

Chillón et al (2016) used questionnaires and a GIS package, analysed using Receiver Operating Characteristic (ROC) curve analysis in their study of active travel among university students in Spain. They found threshold effects of $2.6 \mathrm{~km}$ for walking and $5.1 \mathrm{~km}$ for cycling. These supplement the wider range of perceived facilitators of and barriers to school-related active travel in New Zealand, where both primary and secondary school children preferred active travel modes and understood their benefits (Hinckson, 2016). Many children would like to cycle to school $-40 \%$ in the study by Larouche et al (2016) - although only $2 \%$ actually did so. Personal and family characteristics differed between those wanting to cycle to and from school, compared with other children. This study complements that of Yang (2016), who has developed a framework describing the factors affecting individual's decisions to walk or to select another travel mode for journeys.

Behaviour change is another recurrent theme. Interventions that have a sound theoretical basis are to be welcomed, so I have selected Nehme and colleague's study in this issue as my 'Editor's Choice'. (This article will therefore be 'free to access' for the next 12 months.) They found that the Transtheoretical Model underestimates people's readiness to respond to interventions, compared with the Diffusion of Innovations theory. Diffusion of Innovation also categorises individuals into stages reflecting their readiness to change.

Heesch et al (2016) and Brown et al (2016) have taken advantage of 'natural experiments' (Craig et al, 2012) to study the effects of new bicycle infrastructure. Heesch and colleagues found that a new veloway can increase distances cycled. But does this affect health? Brown and colleagues found that 
current and former cyclists expended more energy than people who never cycled; cyclists expended more energy on their cycling than non-cycling days; and those who cycled for longer had lower body mass index (BMI). They also found high turnover (in both directions) between cycling and noncycling status.

For those who feel less physically able to cycle, or wish to extend their range, e-bikes have been seen by some as an ideal answer (Johnson and Rose, 2015). In this issue, Haustein and Møller (2016) explore individual level factors related to the safety of e-bikes. Unsafe incidents that participants' felt would not have happened on a conventional bicycle was most frequently ascribed to other road users' underestimation of the speed of the e-bike. As a recent pedestrian visitor to a city with high ebike use (apparently primarily as a low cost substitute for car use), I can vouch for how fast these go!

One of the papers in this issue is more controversial, as it poses the challenge whether bus passengers should be encouraged to walk or cycle (Bosehans and Walker, 2016). Although public transport use is generally better for the environment, and non-car users than private motor car use, and there can be physical activity benefits for passengers, Bosehans and Walker argue that bus passengers unhappy with their commute journeys could benefit from moving to active commuting and that a group can be identified who would be more likely to make this change.

Finally, other health impacts of transport are not forgotten. Transport-related air pollution is currently a high priority politically, with much publicity for the deaths attributable to pollutants (RCP, 2016). Jain et al (2016) consider current exhaust emissions from vehicles in Delhi and how different policies could alter these in the future. Modelling different scenarios, they found that introducing mass rapid transit may not result in sufficient modal shift among travellers to reduce exhaust emissions, nor would stringent requirements for fuel emissions in passenger vehicles be sufficient. A combination of such measures combined with other approaches, such as increasing parking fees and facilitating constant bus speed through bus corridors will be required. They then remind us that transport is not only for moving people to their desired destinations; goods also need transport. Jain and colleagues report that including demand for goods vehicles when designing transport policies is important for improving air quality in urban centres. We should also remember that transport needs people to operate it. Mabry and colleagues (2016) have reviewed studies of the health of commercial truck (lorry) drivers. This is a group who by definition have a sedentary job, and travel long distances so might also be assumed to have above average reliance on unhealthy, calorie-dense manufactured food (Flórez Pregonero, 2012). Indeed, the highest obesity prevalence among workers in the USA 1997-2002 and 2004-2011 was found in motor vehicle operators (Caban et al, 2005; Gu et al, 2014). Mabry et al found that abdominal obesity was the commonest component of metabolic syndrome, with other cardiovascular risk factors also common among these middle-aged adults. This paper is based on work presented at the $1^{\text {st }}$ International Conference on Transport and Health in London (Mindell, 2015) so can also be found in the Virtual Special Issue ICTH 2015 (www.sciencedirect.com/science/journal/22141405/vsi).

\section{References}

Blackwell A. A Gentle Introduction to Random Forests, Ensembles, and Performance Metrics in a Commercial System. Citizennet, 2012. https://citizennet.com/blog/2012/11/10/random-forestsensembles-and-performance-metrics/ (Accessed 27 July 2016).

Bopp M, Sims D, Matthews SA, Rovniak LS, Poole E, Colgan J. (2016). There's an app for that: Development of a smartphone app to promote active travel to a college campus. J Transp Health. 3(3): In this issue.

Bosehans G, Walker I (2016). "Daily Drags" and "Wannabe Walkers" Identifying dissatisfied public transport users who might travel more actively and sustainably. J Transp Health. 3(3): In this issue. 
Broadstock DC, Collins A (2016). The demand for 'Active Travel': An unobserved components approach. J Transp Health. 3(3): In this issue.

Brondeel R, Pannier B, Chaix B (2016). Associations of socioeconomic status with transport-related physical activity: combining a household travel survey and accelerometer data using random forests. J Transp Health. 3(3): In this issue.

Brown BB, Tharp D, Tribby CP, Smith KR, Miller HJ, Werner CM. (2016). Changes in bicycling over time associated with a new bike lane: relations with kilocalories energy expenditure and body mass index. J Transp Health. 3(3): In this issue.

Caban AJ, Lee DJ, Fleming LE, Gomez-Marin O, LeBlanc W, Pitman T. Obesity in US workers: the National Health Interview Survey, 1986 to 2002. Am J Public Health. 2005;95:1614-1622.

Chillón P, Molina-García J, Castillo I, Queralt A. (2016). What distance do university students walk and bike daily to class in Spain? J Transp Health. 3(3): In this issue.

Christiansen LB, Cerin E, Badland H, Kerre J, Davey R, Troelsen J, van Dyck D, Mitáś J, Schofield G, Sugiyama T, Salvok D, I, Sarmiento OL, Reis R, Adams M, Frank L, Sallis JF (2016). International comparisons of the associations between objective measures of the built environment and transport-related walking and cycling: IPEN adult study. J Transp Health. 3(4): forthcoming. doi:10.1016/j.jth.2016.02.010

Craig P, Cooper C, Gunnell D, Haw S, Lawson K, Macintyre S, Ogilvie D, Petticrew M, Reeves B, Sutton $\mathrm{M}$, Thompson $\mathrm{S}$. Using natural experiments to evaluate population health interventions: new MRC guidance. J Epidemiol Community Health. 2012; 66(12): 1182-1186.

Flórez Pregonero A, Gómez LF, Parra DC, Cohen DD, Arango Paternina CM, Lobelo F. Time spent traveling in motor vehicles and its association with overweight and abdominal obesity in Colombian adults who do not own a car. Prev Med. 2012; 54(6):402-4.

Gu JK, Charles LE, PhD, Moon Bang K, Ma CC, Andrew ME, Violanti JM, Burchfiel CM. Prevalence of Obesity by Occupation Among US Workers. The National Health Interview Survey 2004-2011. J Occup Environ Med. 2014; 56(5): 516-528.

Haustein S, Møller M (2016). E-bike safety: Individual-level factors and incident characteristics. J Transp Health. 3(3): In this issue.

Heesch KC, James B, Washington TL, Zuniga K, Burke M. (2016). Evaluation of the Veloway 1: A natural experiment of new bicycle infrastructure in Brisbane, Australia. J Transp Health. 3(3): In this issue.

Hinckson E (2016). Perceived challenges and facilitators of active travel following implementation of the School Travel-Plan programme in New Zealand children and adolescents. J Transp Health. 3(3): In this issue.

Hosking J, Mudu P, Dora C (2011). Health co-benefits of climate change mitigation - Transport sector. Health in the green economy. Geneva: World Health Organization.

www.who.int/hia/examples/trspt comms/transport sector health cobenefits climate change mitigation/en/ (Accessed 28 July 2016)

Jain S, Aggarwal P, Sharma P, Kumar P. (2016). Vehicular exhaust emissions under current and alternative future policy measures for megacity Delhi, India. J Transp Health. 3(3): In this issue.

Johnson M, Rose, G (2015). Extending life on the bike: Electric bike use by older Australians. J Transp Health. 2(2):276-83. 
Kurka JM, Adams MA, Gerema C, Zhu W, Cain KL, Conway TL, Sallis JF. (2016). Comparison of field and online observations for measuring land uses using the Microscale Audit of Pedestrian Streetscapes (MAPS). J Transp Health. 3(3): In this issue.

Larouche R, Stone M, Buliung RN, et al. (2016). 'I'd rather bike to school!': profiling children who would prefer to cycle to school. J Transp Health. 3(3): In this issue.

Mabry JE, Hosig K, Hanowski RJ, Zedalis D, Gregg J, Herbert WG. (2016). Prevalence of metabolic syndrome in commercial truck drivers: A review. J Transp Health. 3(3): In this issue.

Mindell JS. 1st International Conference on Transport and Health (ICTH 2015). J Transp Health. 2015;2(2) Supplement:S1

Nehme EK, Pérez A, Ranjit N, Amick BC, Kohl HW (2016). Behavioral Theory and Transportation Cycling Research: Application of Diffusion of Innovations. J Transp Health. 3(3): In this issue. (Editor's Choice)

Pizarro AN, Schipperijn J, Andersen HB, Ribeiro JC, Mota J, Santos MP. (2016). Active commuting to school in Portuguese adolescents: Using PALMS to detect trips. J Transp Health. 3(3): In this issue.

RCP (2016). Royal College of Physicians, Royal College of Paediatricians and Child Health. Every breath we take. London: RCP.

Yang Y.(2016). A dynamic framework on travel mode choice focusing on utilitarian walking based on the integration of current knowledge. J Transp Health. 3(3): In this issue.

Zhang M (2006). Travel Choice with No Alternative: Can Land Use Reduce Automobile Dependence? J Planning Educ Research. 25: 311-26. 